\title{
ARTHROPOD PALEOBIOLOGY
}
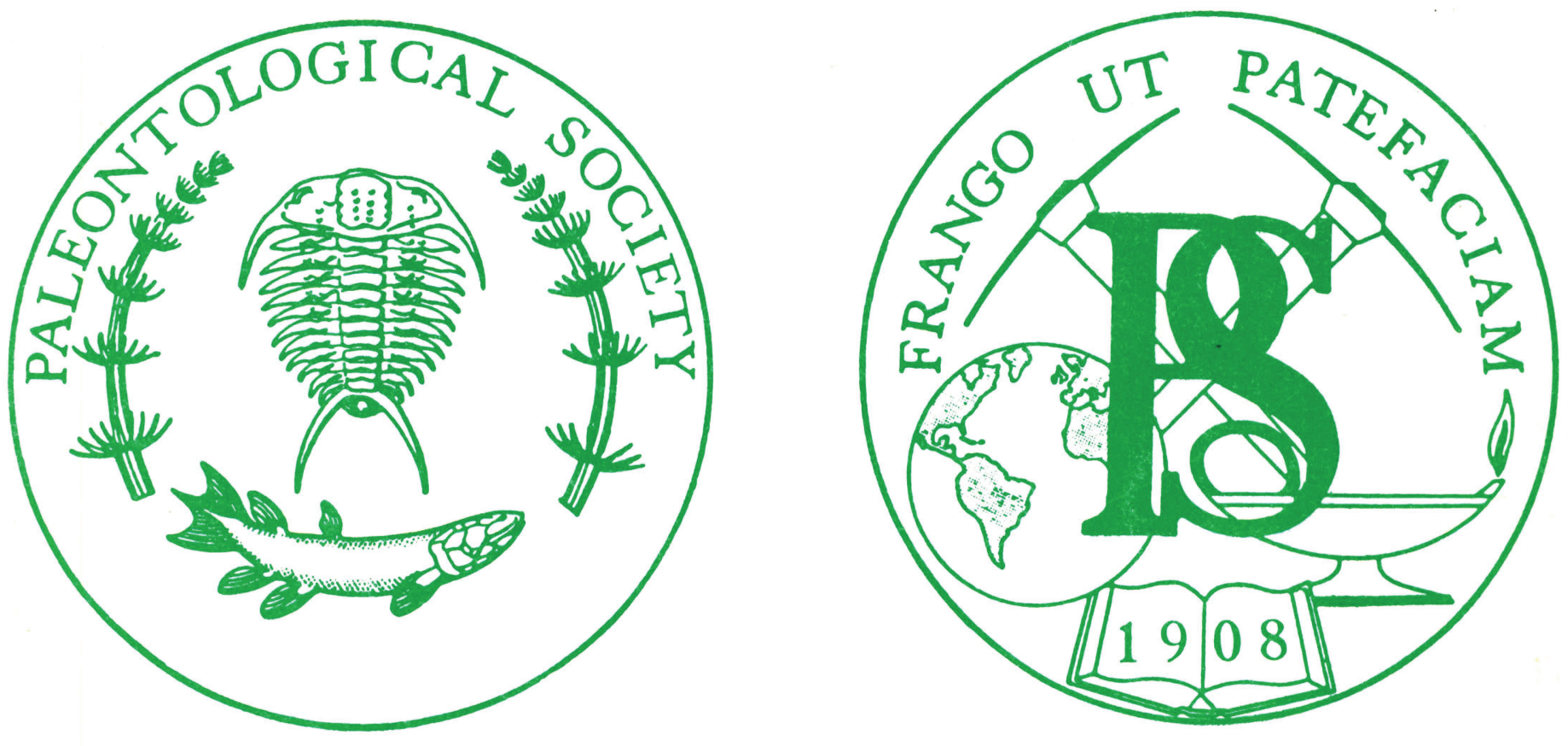

SHORT COURSES IN PALEONTOLOGY

NUMBER 3

1990

convened by Donald G. Mikulic

Stephen J. Culver, Series Editor

A Publication of The Paleontological Society 


\section{ARTHROPOD PALEOBIOLOGY}
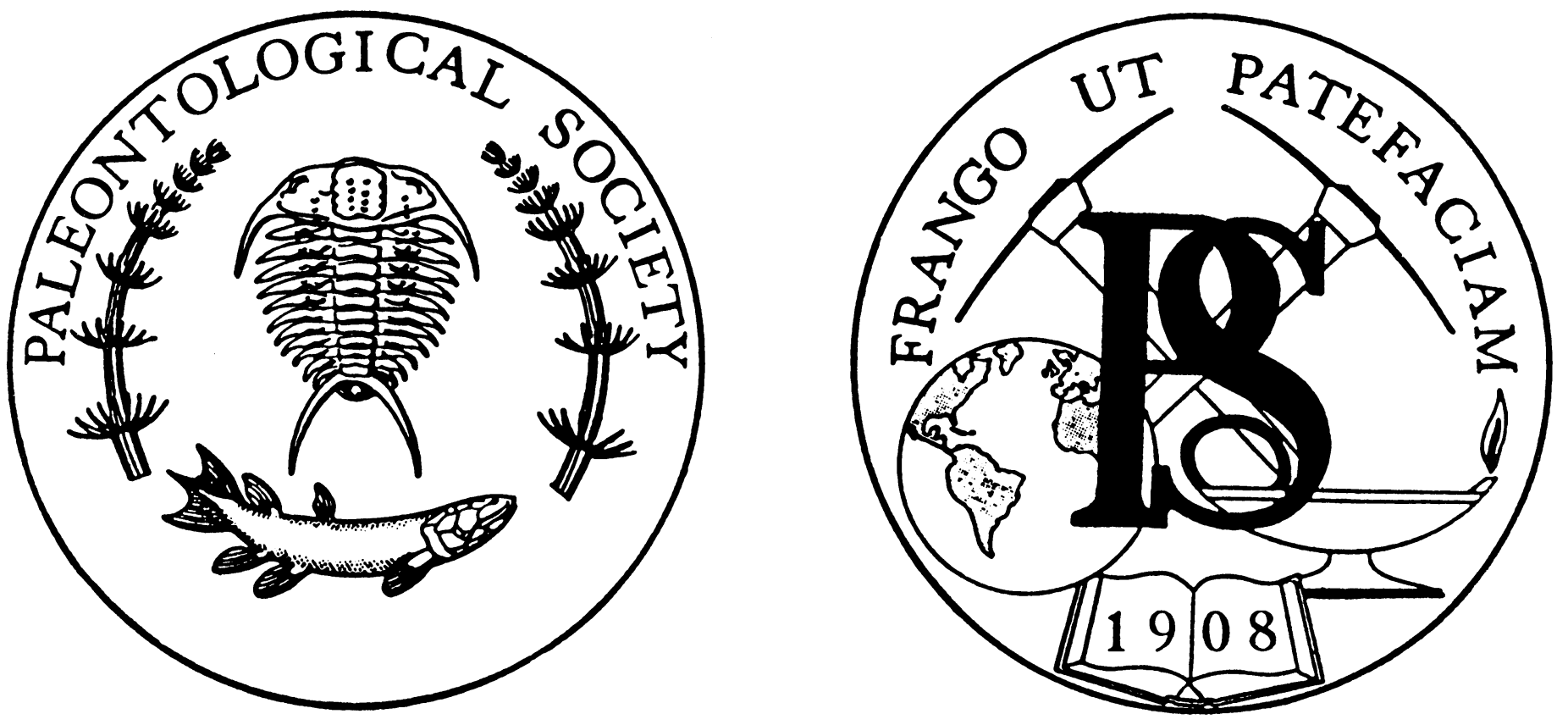

SHORT COURSES IN PALEONTOLOGY

NUMBER 3

1990

convened by Donald G. Mikulic

Stephen J. Culver, Series Editor

A Publication of The Paleontological Society 
PROGRAM . . . . . . . . . . . . . . . . . . . . . . . . . . . . . . $i$ i

PREFACE . . . . . . . . . . . . . . . . . . . . . . . . . . . . . . $i i i$

AUTHORS . . . . . . . . . . . . . . . . . . . . . . . . . . . . . . iv

The Arthropod Fossil Record: Biologic and Taphonomic Controls

on its Composition

by Donald G. Mikulic . . . . . . . . . . . . . . . . . . 1

Early Arthropods: Dampening the Cambrian Explosion

by Derek E.G. Briggs . . . . . . . . . . . . . . . . . . . . . . 24

Trilobite Evolution and Systematics

by Richard A. Fortey . . . . . . . . . . . . . . . . . . . . . . 44

Temporal Patterns in the Arthropod Trace-Fossil Record

by Joanne Kluessendorf and Donald G. Mikulic . . . . . . . . . . 66

Mass Extinction in the Cambrian Trilobite Faunas of North America

by Stephen R. Westrop . . . . . . . . . . . . . . . . . . . 99

Applications of the Study of Trilobite Ontogeny

by Brian D.E. Chatterton and Stephen E. Speyer . . . . . . . . . 116

Trilobite Larvae, Larval Ecology and Developmental Paleobiology

by Stephen E. Speyer and Brian D.E. Chatterton . . . . . . . . . 137

A Novel Hypothesis for the Origin of Biramous Appendages

in Crustaceans

by Michael J. Emerson and Frederick R. Schram . . . . . . . . . 157

Paleobiology of the Arthropod Cuticle

by Roy E. Plotnick . . . . . . . . . . . . . . . . . . . . . . . 177

Silurian-Devonian Terrestrial Arthropods

by William A. Shear. . . . . . . . . . . . . . . . 197

Anthropod Terrestriality

by Conrad C. Labandeira and Bret S. Beall . . . . . . . . . . . . 214

Macroevolutionary Patterns of the Chelicerata and Tracheata

by Bret S. Beall and Conrad C. Labandeira . . . . . . . . . . . . 257

Crustacean Phylogeny

by Frederick R. Schram . . . . . . . . . . . . . . . 285

Decapod Crustacean Paleobiogeography: Resolving the Problem

of Small Sample Size

by Rodney M. Feldmann . . . . . . . . . . . . . . . . . 303 